\title{
Safety Report Nullification Indicator
}

National Cancer Institute

\section{Source}

National Cancer Institute. Safety Report Nullification Indicator. NCI Thesaurus. Code C94071.

Specifies whether the report cancels a previously sent adverse event. 